Journal of the Scholarship of Teaching and Learning, Vol. 21, No. 4, December 2021, pp. 206-213. doi: 10.14434/josotl.v21i4.32936

\title{
Using a Headshot Assignment to Incorporate Critical Theory Into Photojournalism Classrooms
}

\author{
Andrea Briscoe ${ }^{1}$ and Kyser Lough ${ }^{2}$ \\ ${ }^{1}$ Athens, Georgia, United States \\ ${ }^{2}$ University of Georgia
}

\begin{abstract}
This case study uses a diversity and critical thinking exercise in a photojournalism class to show how journalism educators can incorporate race and gender conversations about ethics and judgment into traditionally skills-oriented courses. It is crucial that journalism students learn how to apply their skills properly in an era of social unrest, inequality, and dwindling media trust. Democratic citizenship and journalism are intertwined, but often the bigger ethical conversations are left out of skills-oriented courses. This can lead to a disconnect between the skills themselves and the responsibility of practicing the skills, especially when it comes to matters of power and representation. The field of photojournalism remains predominately White and male, which makes it all the more crucial for students to interrogate their own biases to ensure ethical coverage of their communities. The assignment asks students to make 36 portraits of strangers, and the subsequent classroom exercise has them confront their inherent biases by looking at the demographics of the people they photographed compared to the general population. Data for this case study consist of observations of the classroom conversations and a reflexive journalism exercise the students completed afterward. Findings indicate this exercise is a successful way to introduce racial and gender considerations as part of photojournalistic ethics and judgment. Students initially neglected to think about representation and diversity in their selection of people to photograph but afterward said they could effectively incorporate reflexivity into their work in an effort to provide more representative imagery and confront their own biases.
\end{abstract}

Keywords: journalism pedagogy, photojournalism, journalism education.

\section{Teaching Situation}

The role of journalism education is fraught with a long-standing controversy: Should journalism educators provide vocational training or is it their responsibility to incorporate critical theory beyond skills training? Skills classes give students the tools necessary to carry out journalism, but critical thinking gives them the ethical tools they need to properly report on their communities. In many cases, course instructors may feel pressure to pick a side: skill or conceptual. This case study presents a means to bridge the two by offering a critical thinking exercise within a skills-oriented course. Students sharpen both their photographic skills and their awareness and understanding of race and gender diversity in a community.

Historically, journalism education provided standardization to the occupation, and arguably legitimacy to those working in these spaces early on (Salcetti, 1995). Journalism education is also often correlated directly with preparing students for media jobs. Professionalization is the groundwork for journalism education (George, 2011). It is in these collegiate classrooms where journalism students learn what it means to be a journalist and begin to practice journalism.

When leading a journalism class, then, it is important for educators to think about the ethical implications of the skills, workflow, and information they are presenting to their students. Journalism educators should feel an ethical burden to add critical thinking alongside skills training in their classrooms. Sholle and Denski (1994) argued that it is problematic that journalism educators are 
teaching students to assume roles and match the industry, often at the precise moment scholars and students should be asking critical questions about the industry.

Many journalism courses require students going out into their communities to practice the skills they learned in class to produce a range of content for grades (Graham, 2009). As the industry changes, such as with new technological advancements and digitization, journalism course offerings and learned skills evolve to match the industry standards (Bright, 2018). Students are learning ethical codes and professional standards that the field emphasizes as a part of their professionalization (Donsbach, 2014). It is important, then, for critical approaches to make their way into journalism curriculum alongside hands-on skills training, to equip students not only to succeed, but to better the news industry.

These conversations are particularly important in visual journalism courses, as visuals are an important part of culture. Photojournalists "encode and construct the narratives about our world through powerful images" (Hadland \& Barnett, 2018, p. 2013). Those receiving photojournalism training should be encouraged to think beyond the button-pushing of their camera and to think about how their images are shaping culture, and how they as producers are making decisions that impact the visual stories they tell.

\section{Literature Review}

The notion of objective reporting and finding the truth may be holding journalism educators back from including a critical approach in their classrooms. Objectivity, it has been argued, is a way for journalists to shield themselves from critiques (Tuchman, 1972). The newsroom value of objectivity implies that "journalists' professional and personal experiences are irrelevant ... their identities do not matter" (Steiner, 1998, p. 146). Objectivity takes form in a set of rituals journalists uphold throughout the news-gathering and reporting process (Tuchman, 1972). These rituals can include moral ideals, reporting and editing practices, and patterns of news writing (Schudson, 2001). An objective reporter removes their identity and emotions from their news gathering and delivery, making their news reports unemotional and purely factual (Schudson, 2001). These very rituals and notions of objectivity are contradictory to the foundations of critical theory.

Still, conversations surrounding objective visual reporting are happening among photojournalists working in the industry. In June 2020, a handful of lens-based workers representing several visual journalism and editorial media grassroots organizations published a document titled the "Photo Bill of Rights," aimed at addressing systemic inequalities and harmful practices in the industry. The following statement received attention and generated controversy:

Media institutions cannot claim to educate and progress public understanding of injustices while upholding practices that marginalize workers. The white, Western, cisgender male gaze has been used to colonize, disenfranchise, and dehumanize. The burden of recognizing, accounting for, and living with these inequities has been placed on those with the least access to power, resources, and recourse within the industry. (Photo Bill of Rights, 2020, para. 5).

Many signing onto the Photo Bill of Rights questioned the ability to achieve objective visual reporting, though one organization involved in the bill attempted to offer clarification for photojournalists (National Press Photographers Association Board of Directors, 2020). One photojournalist viewed these sentiments as a "broad-sweeping dismissal of the accomplishments of 75 years of photojournalism, in favor of some newly arrived at, carefully outlined 'enlightened' view of what the REAL purpose of photography ought to be” (Burnett, 2020, para. 13). Another responded

Journal of the Scholarship of Teaching and Learning, Vol. 21, No. 4, December 2021. josotl.indiana.edu 
by claiming the bill recognizes such accomplishments but highlights persisting inequalities that still need to be addressed (Scott, 2020).

These heated conversations among those working in photojournalism further illustrate the need for critical theory in the classroom, to discourage the disconnect between skills and the responsibility of practicing those skills, especially when it comes to matters of power and representation. Critical theory, at its core, encourages students to think about power structures and to question institutions at large. Encouraging students to think about how they gather their news visuals and their visuals' relationship to culture creates media-literate students who can think beyond their assignments and begin to think about the larger ethical implications of their work.

Sending journalism students into communities to complete assignments is an opportunity for students to see and experience new ways of living other than their own (Graham, 2009). And while there is great potential for students to experience empathy and compassion for and dialogue with people with different lived experiences (Graham, 2009), unless students are introduced to critical approaches to understanding news-gathering techniques, then an important educational moment is missing from these experiences (Alemán, 2017; Hoops, 2009).

Without a critical approach to teaching objectivity, scholars have argued, journalism schools are reinforcing systems of power and dominance among races (Alemán, 2017). This issue surfaced again recently in the industry, as people reignited the advocacy for and/or debate over the need to hire and promote the work of Black photojournalists during the Black Lives Matters protests in the summer of 2020 (Matsuda, 2020; Photo Bill of Rights, 2020).

Language and its relationship to race can also be shaping journalism students' educational experiences. (Hoops, 2009). One way journalism education has been critically examined is through the understanding of the role of language. Because of the very nature of the job, journalism instructors place heavy emphasis on language. And language, ultimately, reinforces existing elitist power structures (Hoops, 2009; Pennycook, 2001). With its very specific Associated Press style and inverted pyramid structure, the language in journalism is rigid and standardized (Hoops, 2009). Rules of grammar and language structure are also legitimized by powerful elites (Giroux, 1983; Hoops, 2009; Williams, 2018). Hoops (2009) found that because of the power structures embedded within language in journalism education, international students and students of color often received failing grades in journalism classes or simply chose to drop journalism courses.

This study addresses these concerns by contributing and analyzing one way in which skillsbased courses in journalism schools can incorporate critical theory. For journalism professors to embrace critical theory, however, they also need to question the power structures of the very news organizations that once hired them and where their students are wanting to work.

\section{Research Questions}

The purpose of this case study was to better understand critical educational tools for undergraduate journalism students. This study is an examination of how reflexivity can be practiced in an introductory photojournalism course when discussing issues surrounding diversity. For the purpose of this exercise, our definition of diversity places an emphasis on "the sources and content available to media users" (Napoli, 2011, p. 246). We explored this by addressing the following research questions (RQs):

- RQ1. Do student photojournalists think about representation when creating images?

- RQ2. How do students respond when reflecting on and critiquing their own work through the lens of subject selection and representation?

Journal of the Scholarship of Teaching and Learning, Vol. 21, No. 4, December 2021. josotl.indiana.edu 


\section{Teaching Scenario}

The participants in this study were 21 undergraduate students in two sections of an Introduction to Photojournalism course at a large, public, research university in the southern United States. Each author taught one section. The Introduction to Photojournalism course at this university is the first of three courses in the photojournalism emphasis. The course can also be taken to satisfy a visual requirement in the journalism department and is open to students who do not wish to study photojournalism full-time during their undergraduate career. In fact, the majority of the students in the course belong to the latter group. For most students, this class is their first experience using manual mode with their cameras and thinking about communicating through pictures.

After learning about basic exposure and camera operation, students are given an assignment called 36 Faces, which asks the students to produce vertical headshots of 36 individual strangers in the university community with the following parameters:

- 12 pictures zoomed all the way in, with four in bright light, four in the shade, and four using window light;

- 12 pictures zoomed about half way, with four in bright light, four in the shade, and four using window light; and

- 12 pictures as wide as your lens will let you, with four in bright light, four in the shade, and four using window light.

The students must embed a caption in each image that includes the name, age, preferred pronouns, major/occupation, and hometown of the person pictured. The assignment was announced on January 31, 2020 and was due on February 19, 2020, which allowed students more than 2 weeks to produce these headshots.

On February 21, 2020, the students participated in a classroom activity in each section involving the images they had submitted for the 36 Faces assignment. The first author presented the university's student demographic statistics (age, gender, and race) to the students and then asked students to review their own work to critique and reflect on the diversity and representation in their photographs. They could focus on gender, race, or age. Students were given approximately 20 min to go through their images.

The first author then led a classroom conversation where students discussed why this conversation and reflection process matters and how they could work on improving the representation in their photographs going forward. The second author these conversations and took notes. After the classroom conversation, students wrote and submitted journal reflections discussing the assignment and the classroom activity. All notes and journal entries were anonymized for the analysis portion of this study.

\section{Data Analysis}

After the exercise, the two authors read through the students' written reflections and the second author's observation notes from the classroom. Analysis was carried out in a cyclical manner, with the authors reading through the data several times and discussing points as patterns emerged. While allowing for new themes in the analysis, the authors initially focused on topics relating to the research questions, including experiences with the assignment, experiences in the classroom when discussing the critiques, and news-gathering techniques.

Journal of the Scholarship of Teaching and Learning, Vol. 21, No. 4, December 2021. josotl.indiana.edu 


\section{Solutions and Discussion}

For RQ1, most students did not appear to think about representation when completing the assignment, per their own admission during the class activity. Those who did say they thought about representation said it was on their mind only at the beginning of the assignment and was then forgotten. One student commented in their journal:

I also didn't really think about representation at ALL and I am mad at myself for even saying that wasn't on my mind. I'd like to think if I hadn't been so caught up in completing an assignment for a grade, I would remember that it is important and should be in all my journalistic thought processes.

A few students did mention thinking about it abstractly but made no effort to think strategically about how to put these thoughts into action. The majority of students agreed that they focused on the instructions of the specific assignment and worried about completing the assignment for a grade. Returning to the importance of a grounded professionalization in journalism education (George, 2011), this finding could translate into the professional world, where many journalists think about the specific assignment they've been given and completing it to the satisfaction of a boss or photo editor, instead of the larger impacts their visuals could have on groups of people. The first author also incorporated questions about why these conversations matter into the classroom dialogue. Students saw how the conversation translated to their future careers, with comments such as: "Going forward, I can use this in my professional life by simply being more mindful of how I am representing my town/community and whether my own biases are shaping the news I put out."

For RQ2, students were eager to talk about the assignment experience. Comments from the journal reflections included statements such as:

I feel like the activity was well received and needed. Rarely, do teachers try to get people to reflect on assignments or look for larger overarching themes in assignments and I feel like this was just what students need to prepare them for the real world.

Specifically, we found that reflection and class conversation encouraged students to confront their personal biases. As one student reflected in their journal:

I know for a fact that I have criticized news articles before when they inaccurately represent people for images or reinforce biases. However, as this assignment showed me, sometimes we get so caught up in getting the assignment done that we don't really think about who we are photographing and how that places into larger social issues.

Another student during the class dialogue specifically mentioned how comparing the data to her images revealed her own subconscious bias. Many students discussed how they decided if someone was approachable to photograph. Often, students avoided people with "resting bitch face," as well as perceived "creeps" and "dicks." While these comments often provoked laughter and agreement among students, they did not have a clear definition of how to determine if people were unapproachable beyond their internal feelings and lived experiences. The classroom conversations often turned to how men or women were more/less approachable based on the students' identity, which echoes the importance of understanding how identity impacts news-gathering rituals (Schudson, 2001; Steiner, 1998; Tuchman, 1972) and the need for journalism students to confront this in experiential learning (Graham, 2009).

Journal of the Scholarship of Teaching and Learning, Vol. 21, No. 4, December 2021. josotl.indiana.edu 
Beyond specifically mentioning their own biases, students also discussed how they developed specific news-gathering strategies. An interesting finding was that students discussed using specific focal lengths when photographing different genders. When photographing wide and having to get closer to subjects to fill their frame, students felt more comfortable photographing women. The students were divided on whether approaching individuals or groups was more comfortable; some felt that groups were intimidating, while others noted that groups provided an efficient way to photograph more people. Many students chose high-traffic areas on campus to have access to the greatest number of people.

Another finding in this study showcased how the photographer's identity impacted their newsgathering approaches. Relying on their identity as a student instead of a journalist made completing the assignment more comfortable. Many students chose not to leave campus to photograph their 36 people, feeling that photographing students on campus was easier, because students would empathize with having to get an assignment completed. The few students who went to other places, such as the downtown area, to photograph people left quickly, as they felt uncomfortable or were asked too many questions by the people they were photographing.

Students often reflected on how the assignment encouraged them to think about how to improve their work in the future, making comments such as:

Moving forward, I want to avoid working on auto-pilot. That requires carefully considering who I photograph as well as being fully present with my subjects. When I take photos, I want it to be about the person on the other side of my camera rather than about my grade or meeting a deadline.

The first author found that students mentioned this activity throughout the semester and found it impacted many students' approach to completing their assignments.

\section{Conclusion}

This exercise represents one method of incorporating critical thinking about diversity into a traditional skills-oriented course. It can be easily replicated in photojournalism courses, as well as adapted for other classes, by looking for similar assignments that involve a community focus. For example, asking students to interview community members about a topic.

Our findings show that encouraging students to be reflective introduced critical perspectives on their work as photojournalists and the outcome of their work. Students responded well to the classroom dialogue, a rare opportunity to discuss bias in an applied way, and an invitation to think critically about the importance of representation. Being given demographic data of the community helped students see specifically if they were avoiding certain types of people, such as photographing people of color, by looking at their images. While more radical conversations and approaches could be taken, this is an easy pedagogical tool for encouraging students to confront their own biases.

Providing the time and space to be reflective encourages students to be more aware of potential shortcomings in their work. If newsrooms were to create a space where reflexivity was a part of the news-gathering process, instead of an emphasis on completing a series of tasks, news content might make progress in terms of representing communities more ethically. Students, like many professional photojournalists, may get caught up in completing an assignment instead of reflecting on larger consequences of representation and biases present in their work. Students did not provide unrepresentative visuals because they were malicious, but because they were concerned with the task presented to them specifically.

Journal of the Scholarship of Teaching and Learning, Vol. 21, No. 4, December 2021. josotl.indiana.edu 
These findings indicate that journalism is a product of lived experiences, not objective reporting. Student journalists were impacted in various ways when gathering their images, including subconscious biases and internal feelings on who is or is not approachable. Because newsrooms are overwhelmingly White and male, subconscious biases could impact the news visuals provided. Other factors such as an approaching deadline made student journalists rely on the quickest method of completing their work, which often made students make assumptions about people and places. Teaching students from varying lived experiences to be reflexive in their work could be one way to combat images that stereotype groups or neglect groups altogether.

Teachers should not rely only on lectures when discussing diversity but should incorporate activities that allow students to confront these issues in a hands-on way. Using this teaching method allowed students to think of diversity not as an abstract issue but as a tangible product of their conscious and subconscious decisions. Overall, this study shows that critical conversations in the classroom are a positive experience, with the potential to shift students' approach to work. Incorporating reflexivity into workflow could be a pedagogical tool with positive outcomes for future journalistic work.

\section{Acknowledgments}

The authors wish to acknowledge former student Rebecca Wright for initially inspiring this classroom activity through a reflective blog post about the assignment.

\section{References}

Alemán, S. M. (2017). A critical race counterstory: Chicana/o subjectivities vs. journalism objectivity. Taboo: The Journal of Culture and Education, 16(1), Article 8.

https://doi.org/10.31390/taboo.16.1.08

Bright, A. (2018). Adaptation of journalism curricula in the age of digital media: A qualitative multiple case study of small programs [Unpublished doctoral dissertation]. Indiana State University.

Burnett, D. (2020). Dave Burnett: Letter to the NPPA on ethics. PhotoShelter. https://blog.photoshelter.com/2020/07/david-burnett-letter-to-the-nppa-on-ethics/

Donsbach, W. (2014). Journalism as the new knowledge profession and consequences for journalism education. Journalism, 15(6), 661-677. https://doi.org/10.1177/1464884913491347

George, C. (2011). Beyond professionalization: A radical broadening of journalism education. Journalism \& Mass Communication Educator, 66(3), 257-267. https://doi.org/10.1177/107769581106600306

Giroux, H. A. (1983). Theory and resistance in education: A pedagogy for the opposition. Bergin and Garvey.

Graham, M. A. (2009). The power of art in multicultural education: The international stories project. Multicultural Perspectives, 11(3), 155-161. https://doi.org/10.1080/15210960903116712

Hadland, A., \& Barnett, C. (2018). The gender crisis in professional photojournalism: demise of the female gaze?. Journalism Studies, 19(13), 2011-2020.

Hoops, J. (2009). Analyzing diversity in journalism instruction: A critical race theory case study. International Journal of Diversity in Organisations, Communities \& Nations, 9(1), 87-100. https://doi.org/10.18848/1447-9532/CGP/v09i01/39695

Matsuda, W. (2020, June 11). Why photo editors need to hire Black photographers every day. Aperture. https://aperture.org/blog/talks-interviews/why-photo-editors-need-to-hire-blackphotographers-every-day/

Napoli, P. M. (2011). Exposure diversity reconsidered. Journal of Information Policy, 1, 246-259. https://doi.org/10.5325/jinfopoli.1.2011.0246

Journal of the Scholarship of Teaching and Learning, Vol. 21, No. 4, December 2021. josotl.indiana.edu 
National Press Photographers Association Board of Directors. (2020). Amid today's turmoil, Photo Bill of Rights offers guidance. https:// nppa.org/news/amid-today's-turmoil-photo-bill-rights-offersguidance

Pennycook, A. (2021). Critical Applied Linguistics: A critical re-introduction. Routledge.

Photo Bill of Rights. (2020). Retrieved from https://www.photobillofrights.com/plain

Salcetti, M. (1995). The emergence of the reporter: Mechanization and the devaluation of editorial workers. In H. Hardt \& B. Brennen (Eds.), Newsworkers: Toward a history of the rank and file (pp. 48-74). University of Minnesota Press.

Schudson, M. (2001). The objectivity norm in American journalism. Journalism, 2(2), 149-170. https://doi.org/10.1177/146488490100200201

Scott, A. (2020). My response to David Burnett's open letter to the NPPA. PetaPixel. https:/ / petapixel.com/2020/07/09/my-response-to-david-burnetts-open-letter-to-thenppa/

Sholle, D., \& Denski, S. (1994). Media education and the (re) production of culture. Praeger Publishers.

Steiner, L. (1998). Newsroom accounts of power at work. In S. Allan, G. Branston, \& C. Carter (Eds.), News, Gender and Power (pp. 157-171). Routledge.

Tuchman, G. (1972). Objectivity as strategic ritual: An examination of newsmen's notions of objectivity. American Journal of sociology, 77(4), 660-679. https://doi.org/10.1086/225193

Williams, G. (2018). Sociolinguistics: A sociological critique. Routledge.

Journal of the Scholarship of Teaching and Learning, Vol. 21, No. 4, December 2021.

josotl.indiana.edu 